\title{
Visualisation of Intangible Data of the Cultural Heritage in Field Research and Hermeneutic Analysis
}

\author{
IVAN MURÍN \\ Department of Environment, \\ Matej Bel University in Banská Bystrica \\ maciej.kurcz@us.edu.pl
}

\begin{abstract}
Ethnology and cultural anthropology are characterized by the field research and ethnographic collection of material. Recording and transcription seem to be issues of ethnoscience that have already been resolved many years ago. The relevance of their use in science, e.g. by intercultural comparison,was getting lost with the use of more illustrative and available photo and film recording. Later on, the complicated schemes of interpretation of the empirical knowledge were a burden for the disciplines themselves; they were literally overloaded by sign systems. The issues have been methodologically addressed by resignation to the descriptive documentation. This paper is pointed at the methodological discourse of the visual documentation, visual data analysis and interpretation in research of the cultural heritage.
\end{abstract}

KEY WORDS: field methodology, visualisation, data, hermeneutic analysis, intangible cultural heritage

\section{Introduction}

After the postmodern-enthusiasm about the increasingly vague interpretationalism, it appears to be legitimate to use the field record for those research objects where it is not a burden, nor a meaningful value itself. Studies of the issues of the cultural and natural 
heritage should include a certain comprehensible extent of sign analysis.Syntheses which represent the actual knowledge in multidisciplinary sciences, should be written in a language and terminology accessible to the inter-scientific discourse which should also be reflected by the final summaries of knowledge in the research outputs.

It would be illusory to claim that we could cover all relevant empirical phenomena concerning the topics of the cultural and natural heritage by ordinary field observation and recording. Neither the research potential,nor the methodological possibilities of any of the disciplines mentioned above allows us to do that. By empirical examination we can help ourselves with procedures of research methodology, which seems to be very promising in its development - field ethnography, participative observation, field statistics, transcription and hermeneutic analysis, visual anthropology, visual ethnography, etc.

\section{Terminology}

With the development of the scientific research in different disciplines dealing with the cultural heritage, attempts to define it have been increasing gradually. The same it was with the important prefix of this term - culture. UNESCO has defined cultural heritage in its Draft Medium Term Plan (UNESCO 1989). ${ }^{1}$.As it can be found in this institutionally specified terminology, cultural heritage exists in both tangible and intangible forms (RHISIART 2012b). Tangible heritage includes artefacts, buildings, structures, landscapes, cities, and towns including industrial, underwater and archaeological sites, etc. It includes their location, relationship to the natural environment and the materials from which all these are made, from prehistoric rock to cutting edge plastics and electronic products (ICCROM Working Group 'Heritage and Society" 2005). Intangible heritage, which is important for this paper, includes practices, representations, expressions, knowledge and skills that communities, groups and individuals use and transmit from generation to generation (HAMAR 2013). If we studied heritage by field ethnographic methods, new forms of cultural heritage preservation as digital heritage (LONDON DECLARATION 2004) are inspiring for us. Digital heritage includes texts, databases, still and moving images, audio, graphics, software and web pages. Some of this digital heritage is created from the scanning or converting of physical objects (including man) that already exist and some is synchronically created digitally. Whatever its genesis, it needs constant maintenance and management to be retained. 
A symbol carries a certain emotional value in itself, when, besides obvious meanings, it also transfers an emotion transferred into meaning. Then the symbolic language opens subconscious cognitive meanings that evoke emotional resonance in us. Symbols -triggers of the same or similar emotional connotations can be various icons. Thus a symbol, according to K. Burke, S. Langer, C. Geertz (GEERTZ 2000), can designate any natural phenomenon, object, physical, social or cultural activity.

The sign itself is spread in communication and kept in the society by expedients who reproduce it. It ceases to exist by the loss of its meaning, percipients think of nothing anymore when taking over its meaning, as said by C. Jung (JUNG 1954). They are carriers of the sign, carriers of the meaning, replicators, ... . Symbols can be clues for the percipients, helping them recognize and understand unknown meanings. Carriers of the sign reproduce information in a way that they help other communicants recall the previous experience with similar individuals like the carriers, or, what is even more important for us, verify stereotypes acquired in another way by them. The carriers are expedients of information who choose such narrations, where, from their experience, they know that the listeners also experience conformity between the verification and decoding.

Then interactions are mutual influences of communicants in direct communication, when information exchange takes place. It can be a meeting, i.e. any interaction that takes place during an occasion, by which all communicants are equal. Another way is the performance, i.e. any activity of an individual on a particular occasion, task of which it is to make an impression on any of the communicants. For the interaction - performance to take place, the carriers of the sign get into roles (tasks) which are of great importance in the traditional community.

Then the roles are formulae of communication and acting, set in advance, presented during the communication act, yet taking place on other occasions, mostly by communicants' reproduction. These can be social, profession, communication roles etc. Passing on is one of the vital terms of communication, perceived as a selective generational transmission of information applied in the community connected by some form of cooperation. It is a way of acting which does not require special verification, as it is presumed that it took place in generational selections. Stabilization means adoption of its meanings by the society and it becomes collective representation. It is important also because meanings of terms collective,collectively have been injured considerably by the vulgarization by laymen, which makes it advisable to remind us of C. Jung's and L. LéviBrühl's definition of this term (JUNG 1954:21). At present, more and more attention is paid to the documentation of changes of contents of the collective memory by the documentation of intangible culture (LIPSITZ 2001), as well as forms of transmission - convoys, as its 
contents are conveyed.The increasing interest can be also seen in the rising institutional support of the research of collective memory. ${ }^{2}$

Confrontation and complexity of individual casuistry led C. G. Jung to the examination of the collective spirit, where these collective representations serve to suppress uncontrolled outbursts. This is how an individual can tame conscious behaviour. By the synchronous analysis we can thus support statements about the innateness of some forms or strategies of communication, which are transferred through archetypes. After the threestage generational selection, which ethnologists consider to be a very effective filter for not corresponding interferences, modification of the nature of the value system, only forms of immanent nature of a man should be included in the selection of the socionormative signs.

\section{Visualisation Analysis of the Field Empirical Evidence}

Visual recording of the diverse social reality makes it possible detailed analyse for our study of nearly cabinet (or more laboratory-based) manner. It depends on the decision, what depth of the analysis meets the achievements of our research goals.

The objectives of the research of the cultural heritage mainly lead to:

1. To record or obtain a significant phenomenon, which obviously stabilizes the desired state of co-existence in the community by generational transmissions

2. To interpret it in the interpretation of scientific theorems concerning the preservation of the cultural heritage.

In her introduction to the methodological handbook of visual anthropology (MEAD 1963), M. Meadgives reasons for the use of field visual record in the „scientific discipline of the word" as the trust of the researcher in the later repeated reanalysis from the point of view of more topical analytical and theoretical decisions and perspectives. Such methodological requirement is absolutely justified and so our research team adds film records of the analysed material to our work. As long as the researcher carries out fieldwork just alone with adevice, he needs to decide, what kind of scanning meets his intentions. The objective of the work was to acquire primary data for an analysis. Methods of visual ouvertes.fr/halshs-00926329/document pp.28-29 
IVAN MURÍN

Visualisation of Intangible Data of the Cultural Heritage in Field Research and Hermeneutic Analysis

anthropology (MEAD, BATESON 1977) distinguish two ways of scanning regarding the purpose of the scanning - illustrative and representative scanning.

\section{Ability to Distinguish Heritage Problems in the Field}

Two accesses to the study of the heritage also offer two ways of how to approach the research and how to understand it. Exact sciences approach the understanding of the generational transmission from the position of a well-equipped subject (methods like examination, measuring technology, elaboration). The intellect, however, examines the thing and gives us information about it (PETRUSEK 1993:148), it does not reflect the contraposition of the thing and personality that much. When studying the heritage from the point of view of the man, the methodological error from the approach to the subject, where the subject - communicant would be perceived by the researchers as a thing, would mean only another accumulation of knowledge which has no empirical coverage, i.e. it is little verifiable.

The second way - dialogic one - draws on M. Bachtin's (BACHTIN 1979) original concept of cognition of the thing and personality (inner world). The subject of the research - the man, but also other living beings, as shown by etiologic researches, has his internal contents "in which he always keeps distances". Objects of the understanding must be also excursions into this deep world of the examined subjects. Dialogic recognition of the generational transmission is understood as the recognition of the personality phenomenon carrier who has this inner distance and reveals his personality, e.g. through his traditional role, in communication. The task of the researcher is to acquire the precision of a phenomenon recognition and a certain depth of penetration into it.

Despite the fact that Bakhtin treats comprehensions one of the significant methods of the humanities, he sees no contraposition against natural sciences and exact examination. He expressly emphasizes the necessity of embodying methods of measuring, mathematics and exact documentation of the research issue (BAKHTIN 1979:349). The present-day discussion on Bakhtin's methodological contributions more or less held in debates on the poetry of art in a rather non-critical circle of followers associated around the periodical Bachtinskij sbornik. Bakhtinled directly to the dialectical hermeneutic method of sign analyses (VOROPAJ 2002:662). However, it encounters the issue of the exactness of the transcription of signs in the research of intangible culture. Visual anthropology and the method of visual documentation take transcription as reduction of symbols, and carries out the sign analysis in digitized hermeneutic units and primary documents of direct observation and recording. 


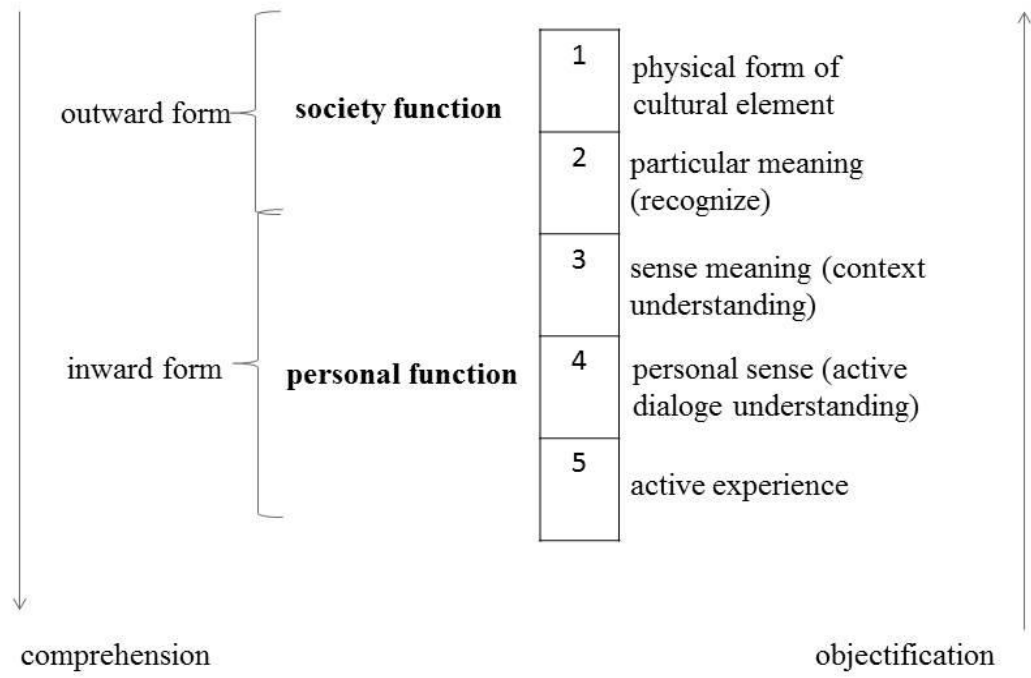

Figure1: Applied Bakhtin's value - axiological model of published (LOI 1982:145) perception of elements of intangible heritage.

When seeking how to understand the transmissions of the immanent value structures in the culture, we have been analytically following Bachtin procedure:

\section{Psychophysiological perception of the phenomenon - sign}

Here we have used the knowledge from visual anthropology, databases of elements of the storing, but also the theory of human ecology, which has been used in the Slovak ethnological science. The dialogue of the researcher and respondent in the field is largely an information exchange between cultural environments of the origin of both communicants. Psychophysiological perception of the researcher is then understood as the ability to decode individual, local, wider cultural meanings of information in time. As the topic reduced like still seems to be too wide, the intention was specified to the research location, where the support in the thematic variety of substances is sought in their delimitation by the generational transmission, local activity and team (I understand team as a territorial community and in the definition stated in the terminological section) sharing of meanings. 


\section{Identification of the known and unknown meaning}

Culturally specific symbols are those created in connection with the cultural variety of the man, and intercultural symbols are those which overlap interculturally due to communication transmission (e.g. mass one). It would be desired to add unknown symbols too. Unknown meanings mainly contain individual "attitudes" - individual language, but often topics too, which are stabilized in the society, community and culture. Such stabilized signs are the subject of our research and we use meanings shared by the local community to denominate their meanings.

\section{Understanding the meanings in a given context}

Contextual determination of the heritage is characterized by topic circumstances. Contextual distinguishing is very important by mechanisms of the transmission. Familiarity with the context, e.g. tradition, is essential by recognizing the so called stabilized forms of behaviour. The context is not presented in the recorded material in researches, but we publish contextual outputs like e.g. video documents. The research outputs themselves seem to be reductionalistic on purpose.

\section{Active dialogic understanding}

This understanding or misunderstanding might be the main criterion of the transmission mechanism. If we assume that each phenomenon of the generational transmission is syncretic, each of its recipients is exposed to certain effort to understand in the changing time. To keep the older socionorms, it holds that possible misunderstanding is partially replaced by the phenomenon of tradition. Several attitudes towards values are based on the symbolic language and, to keep the heritage, it is on especially important symbolic behaviour. Information, topics which transfer sociocultural norms are difficult to understand symbolically, the richness of topics is rather a burden in times of an excess of information.

\section{Qualitative-Quantitative Mix of Field Data}

According to Petrusek (1993:130), dialogical understanding between respondents and the researcher is limited by the knowledge of a specific language, what is extremely important regarding the transmission of information. The members of the researches have conditioned their selection of the field material and location of the research by knowing the material and a long-term interest in the locations. 
Visualisation of Intangible Data of the Cultural Heritage in Field Research and Hermeneutic Analysis

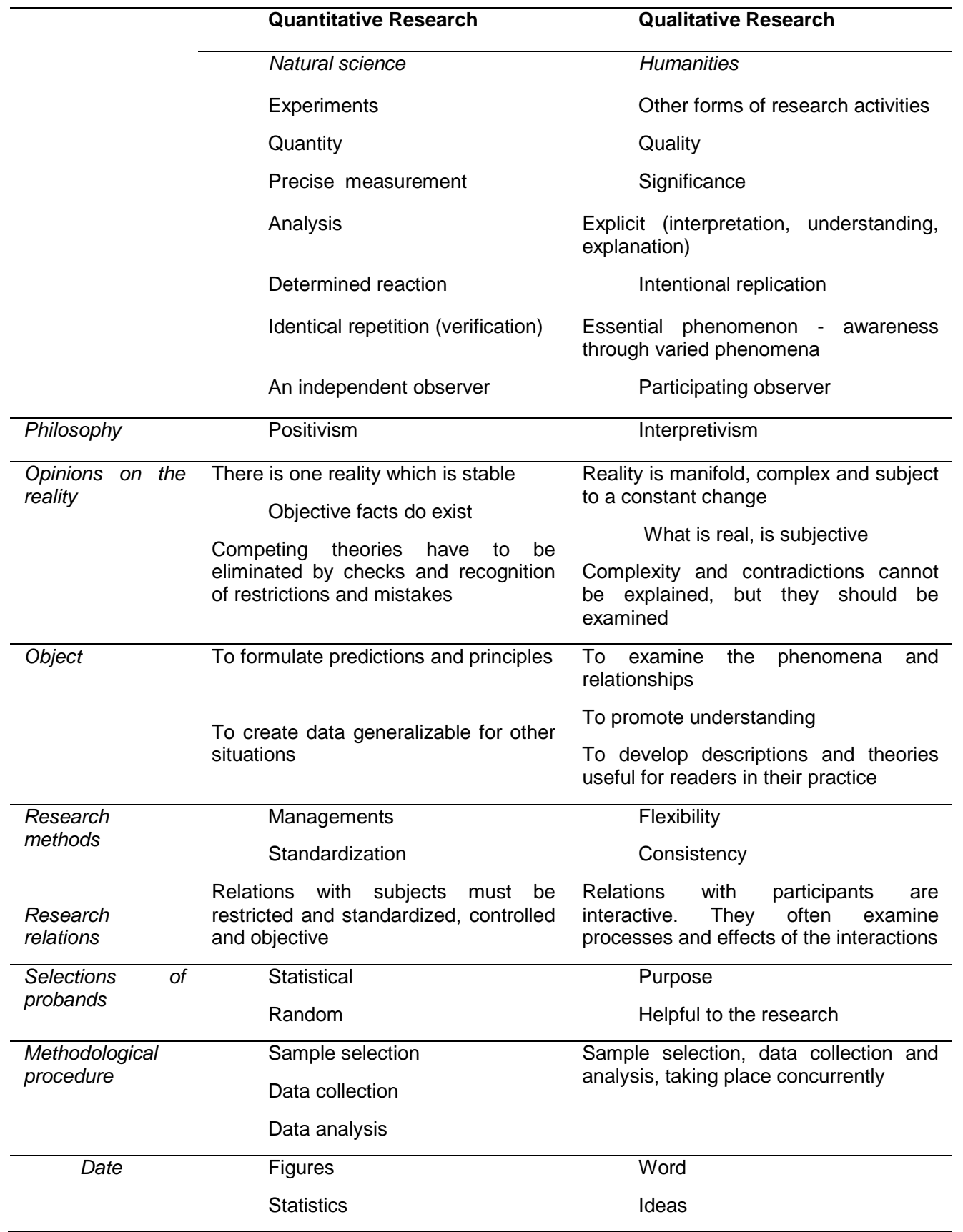

Table 1.: Nature of the approach by anthropology/ethnology field research (HENDL 2005) 
By the research of the signs of field sustainability and looking for situations where they are transmitted, we have drawn on concepts of hidden rules of acting, contact (direct) communication (LEŠČÁK 2000), ethnosemiotics (PETERKOVÁ 2003) and communication symbolic system (LORENZ 1983). Following this concepts we have determined the communicants in the communication from the point of view of understanding the issue of the preservation of the cultural and natural heritage to the carriers who dispose of:

a.) participating understanding - individuals, situation participants

b.) mutual interaction understanding: all situation participants

c.) meta-understanding (third persons - researchers, scientific interpretations and typologies)

These three categories of understanding meanings of the transmitted information can be mutually divergent. Researcher's understanding can be influenced by his preferences, therefore the results of particular studies were subject to validation of the results in the form of their presentation by respondents.

The researcher is exposed to a number of information in the field, which have to be recorded as a whole as much as possible. Both options express the importance of the reality capturing which he shares with the recording device. Illustrative scanning helps the researcher obtain contextual information to the real phenomenon (MEAD 1934). That is how the researcher interferes in the selection of facts, he is usually the scanner himself.

Representative scanning is a stationary type of scanning of the examined phenomenon, constituting simultaneous recording of the phenomenon together with the researcher.The researcher may work on the conduction of the research (interviews, observation) independently on the recording. This method is suitable for recording less dynamic phenomena, by which we can estimate their course. Here we can choose the management of the images. As the record is processed and cut on the site of the research nowadays, we do not have to limit ourselves by the recording material, and we can record long sequences of several hours.

Recommendations of several researchers in the field of sequential scanning have been very inspirational for the research of communication interactions for the ethnographic recording. Sequential scanning is a type of scanning by which the researcher has to recognize the basic sequences of the interview. These sequences are completed by records, sign transcription, audio recording, ethogram, data tables etc. Such scanning seems to me ethical and it doesn't disturb the respondents by the use of the current scanning devices of smaller size, and the researcher can concentrate on conducting the conversation, recording 

Analysis

or detection of what is outside the lens of the device. It also applies to the research of communication, because scanning for communication analysis is not scanning from the point of view of one of the communicants. Unlike a film with a story, the camera is in the position of a recorder of the reality visible by no one (of the participants) (HOCKINGS 1995:286-290).

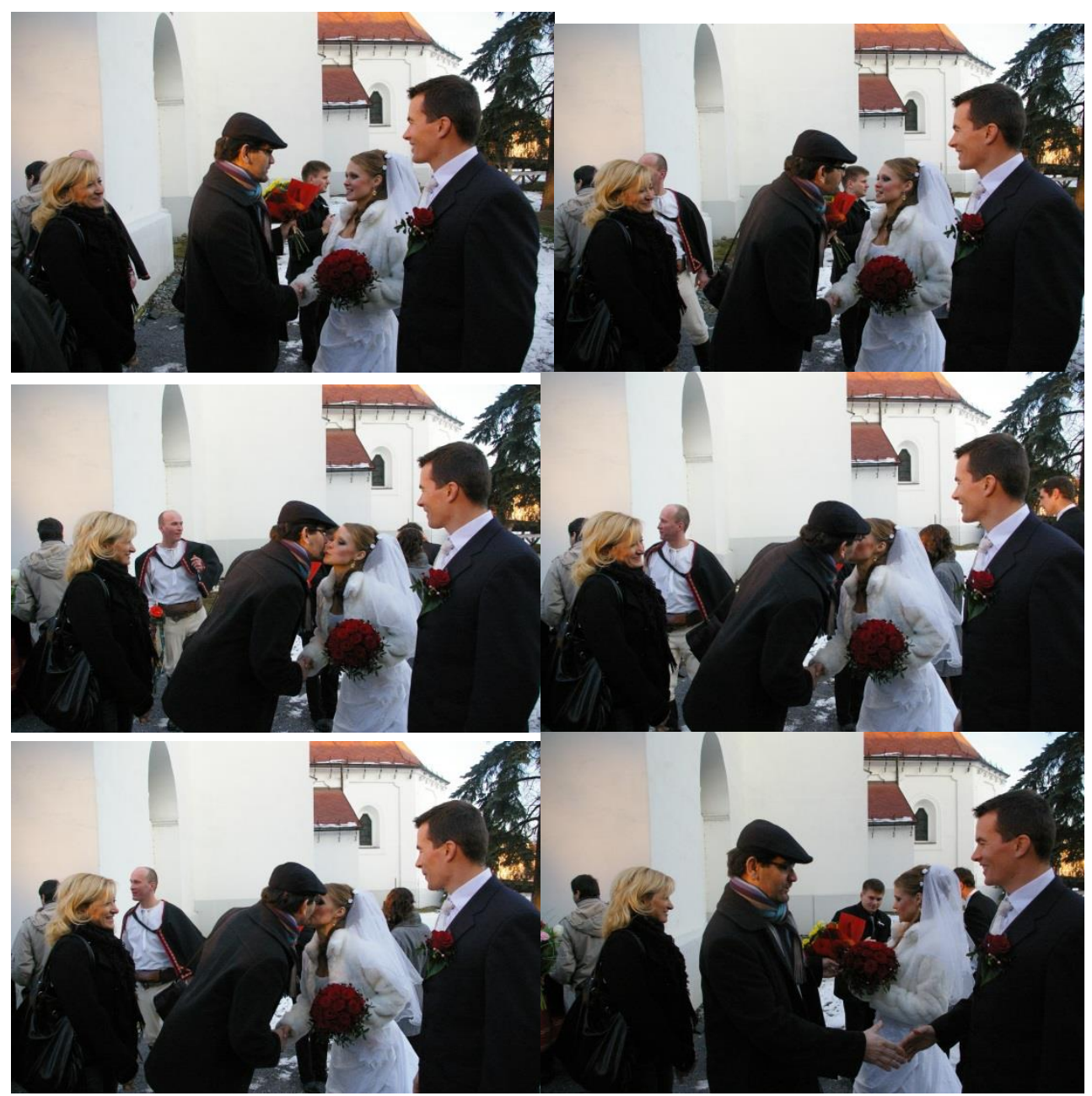

Figure 2: Sequentional scanning after a wedding ceremony (Central Slovakia). Photo: author

Thus acquired video material completes our observation and the record by: 
IVAN MURÍN

Visualisation of Intangible Data of the Cultural Heritage in Field Research and Hermeneutic Analysis

1. Recording the exact time and chromatics of the record in the intactflow of information

2. Recording the nature of particular time sequences regarding the time, place and nature of the place for the interpretation of the data, also by verifying scannings

3. Allowing the qualification of moments when the behaviour and responses of respondents change in time - immediate behaviour, slow reactions, continuous behaviour, changes in the frequencies of the behaviour.

4. Bringing the examined phenomenon closer in detail or slowing it down

5. Allowing to identify the respondent regarding to the ecology of his personality

6. Allowing to identify the environment and supporting interactions

7. Allowing detailed comparing in time (COLLIER 1995:245-246)

The problem of any record lies in limited opportunities to capture an event as a whole. Therefore the researcher must basically choose one of two options. Either to record the context or phenomenon by camera.Both approaches are richly represented in visual ethnography. However, we assume that the contextual view through visual records would "illustrate" the complexity of the particular phenomenon more clearly. Nevertheless, such research requires more teamwork and especially systematic recording in time (MacDOUGALL 1995).

Unlike the anthropological analytical video documentation, the ethnographic video documentation offers certain personal testimony of the ethnographer with the camera in the field. Ethnographic video documentation wants to deliver a certain "story about the culture", what is not included in the anthropologic perspective generally focusing on the phenomenon. The intention of the documentation is to scan the phenomenon in a way that the researcher can interpret aesthetic categories as well. The scanning is difficult, requiring constant operation of the recording device. Even though the issue of reflexivity and subjectivity of the observation and recording of cultural phenomena by the ethnographer in the field is not answered thus, certain validity of data and information is determined by the emic perspective of the abstractor.

\section{Field Hermeneutic Analysis (SEEBOHM 2004) of Symbolic Systems}

Methods of verification of qualitative phenomena are directly connected with the changing ontology of discovering in science. Complexity of the methodological proceeding lies not only in the way of explanation of the knowledge acquired by studying, but also in the way how to recognize, record, describe the empirical signifying phenomena. When 
IVAN MURÍN

Visualisation of Intangible Data of the Cultural Heritage in Field Research and Hermeneutic Analysis

studying the cultural and natural heritage, there is usually some prevailing argumentation supported by its analyses and interpretations from the position of a particular scientific discipline. The situation is even more obscure by the validation of the findings - the range of methods includes a spectrum from metaphysical interpretation to operationalistic definitions. It is a certain forfeit of the topicality of the topic, which wasn't avoided by the study of the natural and cultural heritage. The spectrum of application of methods is wide, the decision-making about the selection of methodological procedures mainly depends on the knowledge of the methods and in the confidence in achieving relevant results by means of them.

The contemporary research is presented in two ways of the explanation of the results. There are interpretative texts with very visual analytical image documentation. It is great explanatory power but small value for systemic comparing, deep findings and validation. On the other hand, there is operationalistic explanation of researches in the form of exact (numeric) outputs. It represents the real depth of the analysis through the ways of measuring and statistical examination. Their interpretation into the form of at least partial interscientific synthesis is very difficult, they use a specific language, results and terminology (WENGRAF 2001). Knowledge usually remains stuck in the partial problem of the particular scientific discipline. Somewhere in between we would like to see the anthropological or naturalistic descriptions and structured analyses, which prevail in the methodology at the moment. It's the destiny of the generalizing sciences like anthropology that nature of the scientific methods is based on relative comprehensibility, which shouldn't reduce their quality though. Their value grows with precision and accuracy. Such methods include transcriptions, which are still a current scientific tool by the use of scanning documentation devices. The use of sign recording and coding are the basic methods of the hermeneutic analysis. Their analysis in the computer interface e.g. ATLAS.ti (FRIESE 2013) solves the long-time problem of the semiotic economization of signs- huge enumeration of symbols. Even though the observation and transcription appear to be anachronism, it is still of importance in the field work. It shows the quality of the researcher- his ability to recognize the problem and to record it primarily. Some methods like structural analysis, cognitive proceedings etc. the observation and recording still have their irreplaceable foundation. However, the first step of the examination of the significants of the sustainable life is to recognize its elements and to understand the information they carry. 
IVAN MURÍN

Visualisation of Intangible Data of the Cultural Heritage in Field Research and Hermeneutic Analysis

\section{The Way of Acquisition and Recording of Video Documentation, Field Research and a Hermeneutic Analysis of Phenomena of Intangible Cultural Heritage by the Author}

Acquisition of the video field documentation regarding the issue of analyses of communication changes of ritual behaviourin present-day wedding rituals has followed in this way :

1. Acquisition of video tapes from wedding cameramen as an indicator of global influences on regional intangible cultural heritage, their digitizing and restructuring of contents according to the successiveness of the wedding ceremonies during 1995-2000.

2. Direct field examination of particular parts of the wedding ceremonies with the objective to add primary field documents which had been omitted by external recorders cameramen during 2000-2005.

3. Field photo documentation as a sign register of non-verbal communication (gestures, facial gestures, proxemics, posturology, haptics) in the field during 2005-2010.

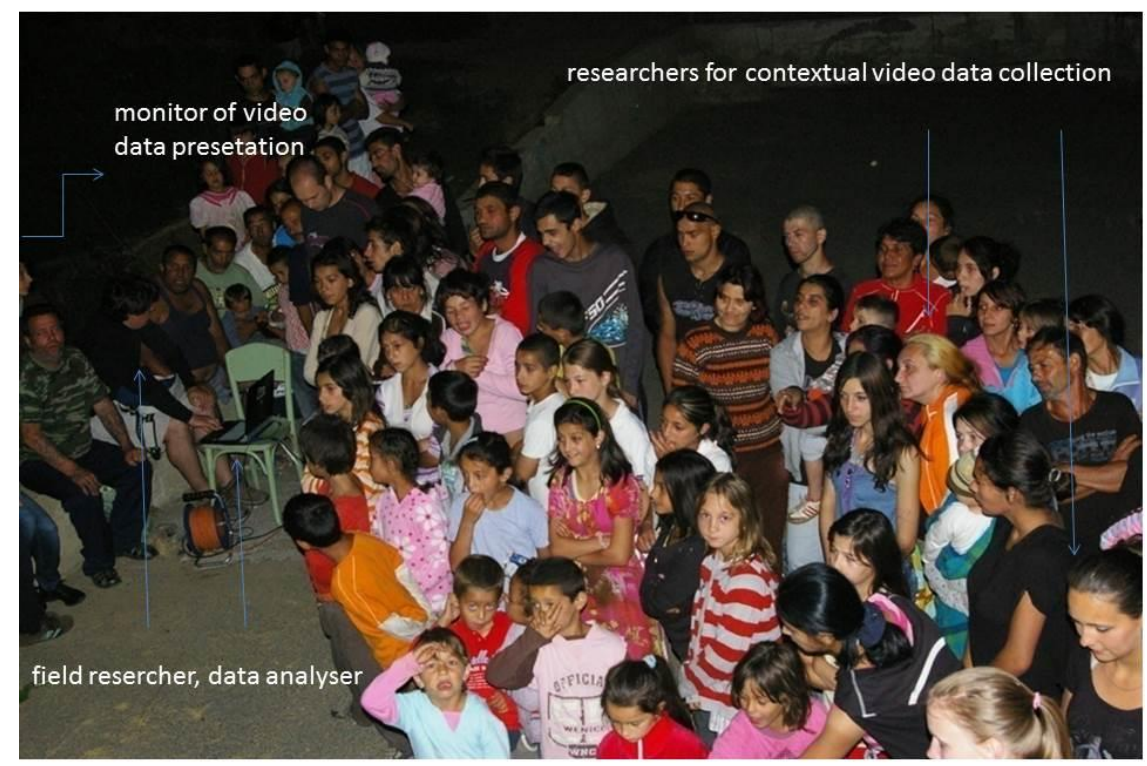

Figure 3: Method of verification of contents of collective memory by means of a group classification and interpretation of the photo and video documentation in the research location of the author-a method of visual ethnography (PINK 2005). 
4. Return documentation of non-verbal discourses of particular communicants in the selected location, which conforms the explanation model from 2010 on methodologically.

5. Verification of ethnological interpretations of the author by the research of field exploration of the contents of collective memory of the community since 2012

The first step of video data processing is to arrange all field findings continuously into primary documents. The primary documents are arranged into common families according to certain criteria: visual field documentation, visually acquired data, contexts, field notes, theoretic determination. Selection of the primary documents is carried out depending on the elaboration of the topic and required ethnological or anthropological interpretation. Analyses of outputs are empirically supported by field transcriptions, photos of nonverbal discourses, video sequences of nonverbal discourses, texts of the interpretation of meanings of the nonverbal communication and technical texts.

\section{Example 1}

The essential procedure by the processing of the field video documentation is to take notes of all recognized meanings the documentation has for each researcher. The analyses in the issue of the nonverbal communication are the subject of specialists in particular modalities of the nonverbal communication (gestures, facial gestures, proxemics, posturology). These notes include analyses from the direct field recorder - ethnographer, fragments of contextsas well assummaries from the field observation, comments onthe application of the theory, graphs, tables, discussions, utterances etc.

Then notes are interconnected and integrated, the most effective way of how to integrate notes into thematic groups is to do it on a daily basis directly in the field in group evaluation of the research team.Such interconnections create more or less consistent thematic texts, which are used by particular researchers by the exploration of their research topics. Taking notes is a continuous open proceeding. It takes place in the field as well as by the processing of the data outside the field. Coding, which is another proceeding, is important for the empirical supporting of ethnological theses.

Field demonstrations of the intangible cultural heritage are symbolic, coding of meanings is carried out according to the meaning structure of Bakthin's concept (see above). However, the line of meanings can be delimited incompletely, e.g. only by context. 


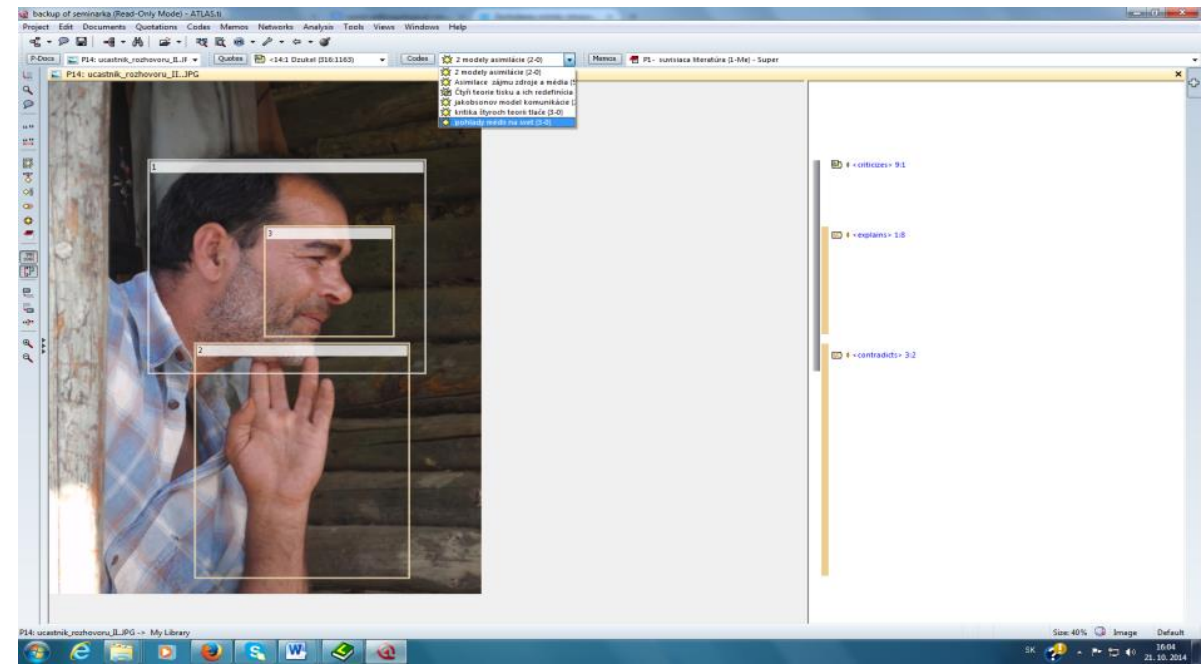

Figure 4: Hermeneutic analysis by author (quotation, coding, memos) of visual field data in ATLAS.ti

\section{Example 2}

By the communication in the wedding ritual, its parts have a quite stable form of a transitional ceremony. Nonverbal discourse and visualized symbolism represent the phases of the transition. So some signs like facial expressions have a quite determined meaning, e.g. crying. Its meaning can be accurate and it can reflect the inner state of the communicant (anger, compassion, despair, hopelessness), or contextual one expressing the dramaturgy of the ceremony - ceremonial crying. Then we assign codes to this nonverbal discourse in the video sequenceof crying- crying as an expressive emotion, crying as a nonverbal discourse. In some discourses, like by long-lasting crying, the sequencing of these codes can alternate.

Methodologically, coding is based on conceptualization and new integration of meanings, it is the basis of analysis, where decision-making for the determination of the code is always the decision-making of the researcher - specialist. But he can use other supporting methods for the interpretation of the visual record for his decisions, e.g.questionnaire examination, statistical detection. Creating networks of codes - concept maps - has an important function by the exploration of findings leading into finding the contents of the collective memory of the examined community. 
IVAN MURÍN

Visualisation of Intangible Data of the Cultural Heritage in Field Research and Hermeneutic Analysis

We postulate that the field output includes pictures, records and film documents. Completion of these information leads through the knowledge basis of the ethnographer. After the verification of his field knowledge by probands in the field, we acquire objectified empirical coverage of theoretical explications. Such output takes place in an actionlikeway,it assumes that also drawing up information from the field will consider this action. If the output of visual anthropology is an analysis, the conceptualization depicts the structure of the knowledge level of the examined phenomenon. Analyses of visual field data are then depicted mainly in topological and semantic concepts. The communicative value of the range of the support of the examined phenomenon of the intangible cultural heritage is represented by complex chronological statistics of all operations carried out by the analyses. The final interpretation of the researches of the intangible cultural heritage by the use of visual ethnography and anthropology is of the nature of objectified hermeneutics.

\section{Bibliography}

BAKHTIN, M. (1979): Estetika slovasnovo tvorčestva. Moskva: Iskusstvo.

BACHTIN, M. (1990): Bachtinskij sbornik. Moskva: Prometej.

COLLIER, J. (1995): Photography and Visual Antropology. In. Paul Hockings. Princips of Visual Antropology. New York: Mouton de Gruyter, pp.250-253.

FRIESE, S. (2013): ATLAS.ti. In. ATLAS.ti Scientific Software Development GmbH. [Online] 25th september 2013.

http://www.atlasti.com/uploads/media/atlasti_v7_manual_201301.pdf.

GEERTZ, C. (2000): Interpretace kultur. Vybrané eseje. Praha: Sociologické nakladatelství.

FELBEROVÁ, M. (2001): Odborná príprava a jej d’alšie komponenty pri filmovom spracovaní národopisných javov. Etnologické rozpravy, No. 1, pp.93-94.

HALBWACHS, M. (1980): The collective memory. Harper \& Row.

HAMAR, J. (2013): The convention for the safeguarding of the intangible culture heritage. In. Slovenský národopis, vol. 61, No. 5, pp. 497-506.

HENDL, J. (2005): Kvalitativní výskum. Základní metody a aplikace. Praha: Portál.

HOCKINGS, P. [ed.]. (1995): Principles of Visual Anthropology. Berlin: Mouton de Gruyer.

CHRISTIAN, P. J. (2012): Memory, Monuments and Conflict. [Online] [26th September 2013.] http://www.academia.edu/1400651/Memory_Monuments_and_Conflict. 
ICCROM Working Group 'Heritage and Society", (2005): Definition of Cultural Heritage. References to documents in history. UNESCO. [Online] 15th January 2005. http://cif.icomos.org/pdf_docs/Documents\%20on\%20line/Heritage\%20definitions.pdf.

JUNG, K. G. (1954): Von den Wurzeln des Bewustseins. Studien uber den Archetypus. Zurich: s.n., Psychologische Abbandlungen, Zv. IX.

KLUCKHOHN, C., KROEBER, A. L. and UNTEREINER, W. (1952): Culture: A Critical Review of Concepts and Definition. s.I. : Vintage Books.

LIPSITZ, G. (2001): Time Passages: Collective Memory and American Popular Culture. In. American culture, Vol. 4.

LOI, A. (1982): Fenomen ponimaniia i kulturno-istoricheskaia ontologiia soznaniia. Comprehension as a Logical-Gnoseological Problem. In. Nauka.

London Declaration. (2004): Sustaining Europe's Cultural Heritage: from research to policy. London: s.n. Online: https://www.ucl.ac.uk/sustainableheritage/conferenceproceedings.

LORENZ, K. (1983): Abbau des Menschlichen (The Waning of Humaneness). Munchen: Piper Verlag.

MacDOUGALL, D. (1995): Beyond Observation Cinema. In. Paul Hockings: Principles of Visual Anthropology. New York: Mouton de Gruyter.

MEAD, G. H. (1934): Mind, Self, and Society. From the Standpoint of a Social Behaviorist. [ed.] Charles W. Morris. Chicago: University of Chicago Press.

MEAD, M. and BATESON, G. (1977): On the Use of the Camera in Anthropology. In. Studies in the Anthropology of Visual Communication. December 1977, vol. 4, Nr. 2, pp.78-80.

MEAD, M. (1963): Anthropology and the camera. In. Willard D. Morgan, Encyclopedia of photography. New York: s.n.

PROFANTOVÁ, Z. (ed.) (2000): Milan Leščák bibliography. In. Folklór a folkloristika na prahu milénia na Slovensku, pp. 15-20.

PINK, S. (2005): Classifying and Interpreting Photographic and Video Materials. In. Doing Visual Ethnography. London: SAGE Publications, pp.94-114.

RHISIART, M. (2012b): JPI Cultural Heritage and Global Change, Report on Drivers of Change and the Future of Cultural Heritage. Paris: Centre for Research in Futures and Innovation, University of Glamorgan, UK with CM International University, research report.

PETERKOVÁ, J. (2003): The Role of Cultural Heritage in the Process of Mutual Communication and Creation of Consciousness of Common Cultural Identity. In. 
Kakanien Revisited. [Online] 20th August 2003.

http://www.kakanien.ac.at/beitr/fallstudie/JPeterkova1.pdf.

PETRUSEK, M. (1993): Teorie a metoda v moderní sociologii. Praha: Karolinum.

SEEBOHM, T. (2004): Hermeneutics. Method and Methodology. In. Contributions to Phenomenology, Vol. 50., Springer, p. 272.

UNESCO, (1989). Draft Medium Term Plan. 25, vol. C, 4.

VOROPAJ, T. S. (2002): Človek vo svete slova: Michail Michailovič Bachtin (18951975). In. Filozofia 9, vol. 57, pp. 651-666.

WENGRAF, T. (2001): Qualitative Research Interviewing: Biographic Narratives and Semistructured Methods. London: SAGE. 